\title{
Copyright Policy and Practice in Electronic Reserves among ARL Libraries
}

\section{David R. Hansen, William M. Cross, and Phillip M. Edwards}

This paper presents the results of a survey of $110 \mathrm{ARL}$ institutions regarding their copyright policies for providing electronic reserves. It compiles descriptive statistics on library practice as well as coding responses to reveal trends and shared practices. Finally, it presents conclusions about policy making, decision making and risk aversion in ARL institutions.

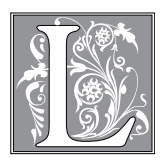

egal issues present important and unusual challenges for academic librarians. Despite the ways in which legal regimes such as free speech, intellectual property protection, privacy, and contract law often shape library practice, few librarians may have substantial graduate-level training in this area. ${ }^{1}$ As a result, decisions with legal implications are often made (particularly by front-line librarians) with an incomplete understanding of the nuanced issues involved. ${ }^{2}$

To support day-to-day operations, many libraries generate policies"framework[s] within which individuals can exercise judgment" ${ }^{\prime 3}$ - for library practice within specific legal areas. Privacy policies, copyright policies, licensing policies, and the like can be invaluable tools, initially crafted by legal experts and then put into practice by librarians and staff on a day-to-day basis; however, the content and structure of policies can vary substantially from institution to institution, particularly in cases where a model policy, proposed by a professional organization such as the American Library Association, is absent. Further, institutions may have limited or idiosyncratic access to policies from other institutions, making it difficult to conduct a systematic review of peer institutions' policies to share information or establish a coherent set of best practices.

Establishing best practices for interpreting and adhering to copyright law is especially difficult in the context of electronic reserves (e-reserves) services. Both law and practice in this domain are less established than in many other areas of copyright law such as first sale or archival activities. ${ }^{4}$

Because e-reserves generally incorporate works protected by copyright, a library must consider many legal issues. Copyrighted works can be used

David R. Hansen is Digital Library Fellow at the University of California Berkeley School of Law; e-mail: dhansen@law.berkeley.edu. William M. Cross is Director of the Copyright E Digital Scholarship Center at North Carolina State University; e-mail: wmcross@ncsu.edu. Phillip M. Edwards is Instructional Consultant in the Center for Teaching Excellence at Virginia Commonwealth University; e-mail: pmedwards@vcu.edu. (C) 2013 David R. Hansen, William M. Cross, and Phillip M. Edwards, Attribution-NonCommercial (http:// creativecommons.org/licenses/by-nc/3.0/) CC BY-NC 
in e-reserves in some situations without permission based on specific copyright exceptions such as fair use ${ }^{5}$ or the Technology, Education and Copyright Harmonization Act of 2002 (TEACH Act). ${ }^{6}$ These exceptions are important but can be difficult for librarians without legal expertise to apply.

Works may also not require permission if they are in the public domain in cases where copyright has expired or based on their status as government works. This calculation can also be complicated by an arcane system of formalities, renewals, and reversions. ${ }^{7}$

Works that do require permission can be handled in a variety of ways. Some libraries contact rightsholders directly but this can raise issues when a rightsholder is difficult to locate or unresponsive. Licensing clearinghouses such as the Copyright Clearance Center may offer a simple point of contact, but some scholars have objected to the CCC's practices that require fees for out-of-copyright works or misstate the law. ${ }^{8}$ Overall, the law is complex and the solutions currently available are imperfect.

The decision to develop e-reserves is further complicated by the nature of these collections, which are often made available at the request of instructors for a limited time. ${ }^{9}$ The individuals responsible for maintaining e-reserves services may have little formal legal or, in the case of paraprofessionals, library training. Because copyright doctrines such as fair use or the idea-expression dichotomy are inherently ambiguous, reliance on a detailed copyright policy alone can transform a thorough rights analysis into a rote exercise that can either over- or underestimate the "true" bounds for permissible use of copyrighted works. Policies that give interpretive license to those on the front lines of implementing the rights analysis may result in varied application across institutions; the same assertion could be made within a single institution when the policy is applied by different staff members. These ambiguities suggest that it is essential to understand both who creates and who implements copyright policies in the e-reserve services context.

While an examination of university copyright policies alone is a useful exercise, and one that this study incorporates to some extent, a more complete picture of the state of current library practices is necessary. As the recent litigation involving Georgia State University's e-reserve service makes clear, evaluation of actual practices (rather than policies in isolation) is needed to discern the legal implications of a particular copyright management system. In the Georgia State University litigation, which is specifically focused on the institution's responsibility to implement and enforce copyright law in its e-reserves system, the presiding judge, Orinda Evans, conceded that the Georgia State Copyright Policy "seems comparable to, and in many cases far more comprehensive than, the copyright policies instituted by other colleges and universities." 10 Judge Evans nonetheless insisted-and rightly so-that Georgia State offer proof of how the copyright policy is implemented in practice. Thus, this study seeks to simultaneously evaluate policy and practice to gain a more complete picture of how libraries evaluate and manage copyright-associated risks.

In focusing on both policy and practice, this study takes the pragmatic view that managing copyright compliance in complex and changing areas like e-reserves services has largely become an exercise in risk management. Unlike many legal risks, however, copyright-associated risks cannot be eliminated solely by educating oneself on the scope of the law for a particular area; much of copyright law is context-specific, depending on the legal definitions and, more fluidly, current copyright norms and practices that help to delineate permissible uses from impermissible ones.

Whereas licensing and rights management has already become a major part of library practice, risk analysis is of particular concern with e-reserves because 
of the uncertain and context-specific nature of copyright law. For services like e-reserves, the rights analyst may typically try to address two questions: First, is the work already available under an institutionwide license (or is there an affordable license available specifically for this kind of use)? And, second, is posting the work permissible under the fair use exception to copyright? To address the question of fair use, one must balance the four fair-use factors, one of the most difficult to characterize of which is "the effect of the use upon the potential market for or value of the copyrighted work." ${ }^{\prime 11}$

Because the potential market must include licensing options, the first question (license availability and access) is related to the second (fair use) in such a way that, as licensing schemes become more common, the counteracting fair-use argument becomes less compelling. This feedback loop may result in the scope of uses that are considered "fair" being obscured and diminished by the expanding availability of contractually licensed content. Although there have been calls to "flex[] fair use muscles on campus," ${ }^{12}$ the high financial and legal risks associated with an "incorrect" fair-use determination force many academic libraries to adopt the riskaverse approaches of licensing content or obtaining appropriate permissions when at all possible. Law Professor James Gibson describes the result as "a steady, incremental, and unintended expansion of copyright, caused by nothing more than ambiguous doctrine and prudent behavior on the part of copyright users."13

To mitigate risk in this area and to reduce potentially harmful feedback effects as a result of risk aversion, it is essential that librarians understand both copyright law and the associated practices among professionals at peer institutions. To date, there is little data available about professional practice in this area, leaving many librarians uncertain about the limits ascribed in their own e-reserves' copyright policies, particularly about the boundaries between seeking permission from rights holders or reasonably relying on copyright exceptions. This places library decision-makers in an uncomfortable position, one that may have the unintended consequence of harming libraries and the legal protections they rely upon. ${ }^{14}$ Further, there is even less data about the ways in which rights holders react to various library policies. This information asymmetry leaves library decision-makers in the dark not only about general practice in the profession but also about the consequences of policy decisions.

The present study addresses three major research questions: how and by whom are current e-reserve copyright policies developed, updated, and implemented; what are current copyright and licensing practices related to actual implementation of e-reserves services; and what, if any, reactions have those policies or their implementation received by stakeholders (such as publishers and rightsholders) external to the institutions?

\section{Literature Review}

Copyright law has long been a topic of interest to librarians, and, as libraries respond to the need for electronic materials, the need for explanatory literature has only increased. A search of Library and Information Science Abstracts (LISA) reveals that, in the last five years alone, over 1,200 scholarly articles have been published on the subject of copyrighta number that rivals the total number of copyright-related articles indexed over the previous twenty years. Among those studies are several major attempts to inventory how universities and their libraries deal with intellectual property rights among students, faculty, libraries, and rights holders outside the university. ${ }^{15}$ These studies largely focus on the copyright policies that universities create to address the ambiguities of ownership and use of copyrighted works.

In the domain of e-reserves services, most of the existing literature discusses rights analysis and copyright policies as a component of an individual library's 
implementation of a particular e-reserves system. For example, in one article, librarian Leah McGinnis explains the implementation of a copyright management system at the University of North Carolina at Chapel Hill following the successful implantation of an e-reserves system. ${ }^{16}$ Similarly, librarian Victoria Wagner of William Paterson University describes how the university library serves as the institution's "copyright touchstone" by implementing procedures for seeking permissions and conducting fair-use analyses for e-reserves. ${ }^{17}$ In these studies, there is little discussion of how those policies and practices compare to other similarly situated institutions.

One study by Gould, Lipinski, and Buchanan present the results of a "systematic study of research library policy regarding application and interpretation of copyright law to reserves and electronic reserves" based on a 2003 survey of ARL member libraries. ${ }^{18}$ Conducted over eight years ago, this study specifically examined photocopied reserves and how contemporary policy and practice of research libraries was at odds with the developing law related to fair use and photocopying. In that context, Gould, Lipinski, and Buchanan criticize as uninformed the application of arbitrary and varied restrictions on photocopying to within rigid page or percentage limits. A similar criticism may ring true for current e-reserve policies and practices, as e-reserves librarians attempt to manage copyright-infringement risk without an accurate understanding of the context and practice of peer institutions. The current environment, with electronic rights management and the proliferation of licensing schemes, requires a more penetrating analysis of how libraries are adapting to these new models.

\section{Method}

The present study focuses on professionals' self-report and interpretation of copyright law in libraries' decisions to license and/or make content accessible to students via electronic course reserve systems. The researchers recruited participants from among 125 Association of Research Libraries (ARL) member institutions. Names and e-mail addresses of potential participants, those holding titles such as "copyright specialist," "e-reserves coordinator," or "copyright officer" were identified at each ARL member institution from publicly available online directories and/or staff listings on libraries' websites. Fifteen ARL member institutions, those that were not higher education institutions, were excluded from this study under the assumptions that (1) their policies and practices might be substantially different from academic institutions and (2) these institutions were less likely to have comparable e-reserves services in place.

Each potential participant received a recruitment message via e-mail with a link to an online survey, active for four weeks beginning in March 2011. Survey participants were asked questions regarding their institution's e-reserve copyright and licensing policies, with a focus on (1) e-reserve copyright policy creation and maintenance, (2) implementation and enforcement of e-reserve copyright policies, and (3) e-reserve copyright policy challenges and resolutions [see Appendix A]. Each participant was also asked either to upload or to provide a link to an online document containing their institution's e-reserve service copyright policy. The online survey uses skip logic to present participants with questions that were relevant to their current practices on their campuses.

Responses to close-ended questions are reported below in the form of descriptive statistics; responses to open-ended questions and supplied documents were subject to inductive coding for emerging themes. Data provided by participants was paired with basic institutional data such as enrollment levels, which were taken from the IPEDS data center, ${ }^{19}$ for U.S. institutions, and from university websites for Canadian institutions. More detailed information was gathered from institutional web pages about each par- 
ticipants' institution (for instance, number of courses offered, library collection size, library budget) to enable the researchers to analyze how institutional characteristics may be related to the reported practices and policies at various types of academic institutions.

\section{Results and Discussion}

Staff members at thirty-five of the 110 ARL libraries recruited for this study elected to participate, for a response rate of approximately 32 percent. Respondents' response rate for particular survey questions varied, however, and only eight elected to provide information on e-reserves statistics for the number of courses using e-reserves, number of items in e-reserves, and licensing information for e-reserves content. Grouped by full-time enrollment, there were thirteen respondent institutions with fewer than 24,000 students, fifteen with between 24,000 and 30,000, and eleven with more than 30,000 students.

Of those thirty-five respondents, thirtytwo $(91 \%)$ reported that their institution made educational materials available through an e-reserves system, and thirty $(86 \%)$ had policies in place that governed the inclusion of copyrighted materials in e-reserves. More than half (15) of survey respondents with existing policies in place indicated that their policy had been evaluated or updated in the last year, and more than 80 percent reported updating or evaluating their policies within the last five years (see table 1).

\section{Policy Creation}

With respect to the process of policy creation, respondents relied on a variety of sources within their home institution as well as information from peer institutions and professional organizations. Seventeen of the thirty-five ( $49 \%$ of respondents) reporting institutions relied on published best practices and guidelines created by professional institutions such as the American Library Association's Guidelines on Fair Use and Electronic Reserves. ${ }^{20}$ The use of published guidelines and best practices may loosely correspond with the size of the institution; only three of the thirteen small institutions (23\%) reported using these resources, but six of the fifteen medium institutions (40\%) chose to do so. Most strikingly, eight of the eleven large institutions relied on guidelines and best practices, better than 72 percent.

Examination of peer institution policies was another commonly reported source, with fifteen of the thirty-five responding institutions (42\%) relying on copyright policies from peer institutions to shape their own policies. Unlike the reported usage of best-practice guidelines, there appears to be little connection between institution size and reliance on peer institution policies.

There is, of course, substantial overlap of use of these types of resources, with many institutions using both-or neither-peer institution policies and published guidelines. Many of these institutions also reported using on-campus expertise when shaping their policy. Seventeen of the thirty-five responding institutions (48\%) collaborated with university counsel or similar institutional attorneys when creating their policies. Large institutions appear to be more likely to consult

\begin{tabular}{|l|c|c|c|}
\hline \multicolumn{5}{|c|}{ TABLE 1 } \\
Currency of E-reserves Copyright Policy-Evaluated or Updated \\
\hline Answer & $\begin{array}{c}\text { Small Institutions } \\
\text { (under 24,000) }\end{array}$ & $\begin{array}{c}\text { Medium Institutions } \\
(24,000 \text { to 30,000) }\end{array}$ & $\begin{array}{c}\text { Large Institutions } \\
\text { (over 30,000) }\end{array}$ \\
\hline Within the past 2 years & 4 & 5 & 6 \\
\hline 2 to 5 years ago & 2 & 2 & 2 \\
\hline More than 5 years & 1 & 1 & 1 \\
\hline
\end{tabular}


TABLE 2

Sources Referred to When Drafting/Updating E-reserves Copyright Policy

\begin{tabular}{|l|c|c|c|}
\hline Answer & $\begin{array}{c}\text { Small Institutions } \\
\text { (under 24,000) }\end{array}$ & $\begin{array}{c}\text { Medium Institutions } \\
(24,000 \text { to 30,000) }\end{array}$ & $\begin{array}{c}\text { Large Institutions } \\
\text { (over 30,000) }\end{array}$ \\
\hline $\begin{array}{l}\text { Best practices or guidelines } \\
\text { produced by professional } \\
\text { organizations }\end{array}$ & 3 & 6 & 8 \\
\hline $\begin{array}{l}\text { College/university legal } \\
\text { counsel on your campus }\end{array}$ & 4 & 5 & 7 \\
\hline $\begin{array}{l}\text { Peer institutions' copyrighted } \\
\text { materials policies }\end{array}$ & 5 & 4 & 6 \\
\hline $\begin{array}{l}\text { Scholarly communications } \\
\text { librarian on your campus }\end{array}$ & 3 & 2 & 0 \\
\hline $\begin{array}{l}\text { Solicited input from the } \\
\text { faculty council or a faculty } \\
\text { committee on your campus }\end{array}$ & 1 & 1 & 0 \\
\hline $\begin{array}{l}\text { Solicited input from } \\
\text { professionals via electronic } \\
\text { mailing lists or other } \\
\text { communication venues }\end{array}$ & 1 & 2 & 1 \\
\hline Other sources & 2 & & \\
\hline
\end{tabular}

with counsel $(87 \%)$ than small $(30 \%)$ or medium-sized (33\%) institutions.

Several institutions also reported working with a scholarly communication officer, copyright officer, or similar legal and library expert. Eight of the responding institutions (22\%) reported doing so, a number that should be read in light of the fact that these positions titles and responsibilities are still somewhat rare and idiosyncratic nationally (Cross, 2011). As these positions proliferate and consensus builds about professional titles and roles, these positions may be used more frequently.

A very small number of institutions also solicited input directly from faculty members. Three institutions reported soliciting input from faculty members or a faculty committee with no large institutions doing so. Similarly, two institutions reported soliciting information from professional listservs, mailing lists or similar professional communication tools.

The missing element for many respondents is direct communication between institutions. Although the majority of respondents indicated that they examined the publicly-available documents from peer institutions, only two institutions reported actually communicating directly with their peers about these issues. The majority of institutions seem to be peeking over others' shoulders rather than engaging in a direct conversation about their practices and experiences.

\section{Policies in Practice}

As discussed above, creating a policy represents only part of an institution's copyright activity in this area. Implementing and maintaining the policy, as well as making the ongoing judgment calls inherent in these decisions, plays an equally important role in university activity. This involves both the day-today activity of frontline librarians who administer the policy and an ongoing role monitoring adherence. This survey asked institutions to describe what types of workers had primary responsibility for monitoring adherence.

Here there is a clear preference for paraprofessional staff to monitor ad- 


\begin{tabular}{|l|c|c|c|}
\hline \multicolumn{4}{|c|}{ TABLE 3 } \\
\hline & $\begin{array}{c}\text { Small Institutions } \\
\text { (under 24,000) }\end{array}$ & $\begin{array}{c}\text { Medium Institutions } \\
(24,000 \text { to 30,000) }\end{array}$ & $\begin{array}{c}\text { Large Institutions } \\
\text { (over 30,000) }\end{array}$ \\
\hline Answer & 0 & 1 & 1 \\
\hline $\begin{array}{l}\text { Your Director or other member } \\
\text { of the library's administrative } \\
\text { team }\end{array}$ & 0 & 0 & 1 \\
\hline $\begin{array}{l}\text { Your copyright officer or } \\
\text { scholarly communications } \\
\text { librarian }\end{array}$ & 1 & 0 & 2 \\
\hline $\begin{array}{l}\text { One or more librarians who } \\
\text { directly administer e-reserves }\end{array}$ & 6 & 7 & 4 \\
\hline $\begin{array}{l}\text { One or more paraprofessional } \\
\text { staff members who directly } \\
\text { administer e-reserves }\end{array}$ & 0 & 0 & 0 \\
\hline $\begin{array}{l}\text { Faculty and instructors on your } \\
\text { campus }\end{array}$ & & & \\
\hline
\end{tabular}

herence to e-reserve copyright policy. Seventeen of the thirty-five respondents $(48 \%)$ rely on staff. The next largest group, librarians who administer e-reserves, was selected by only three institutions ( $8 \%$ ). Two others (5\%) indicated that the library Director was responsible for monitoring adherence.

Reliance on staff was particularly common for small and medium institutions. Of the seventeen institutions that reported using staff, six (35\%) were small and seven ( $41 \%)$ were medium, with only four large institutions doing so.

\section{Administering E-Reserves}

To better understand how ARL institutions actually implement e-reserve systems, the survey asked a number of questions designed to elicit quantitative data for the three-year period spanning from 2007 to 2010 regarding the number of courses with e-reserves offerings and the total number of items made available through the e-reserves system for each year. The response rate for these questions was just under 10 percent, compared to 32 percent for policy-related questions. Unsurprisingly, the response rate for these questions was lower than the response rate for the policy-related questions, raising the possibility that respondents either do not have this information or are uncomfortable sharing it. The inference that respondents simply do not keep track of these kinds of statistics is borne out by some of the comments respondents attached to their question response, noting that the reports were a "best guess estimation." Others were unable even to guess, stating "[w]e can't run a report like this without a LOT of work." Tables 4 and 5 give descriptive statistics for the responses that were collected.

Although the responses might be suggestive of a connection between the level of enrollment at a given institution and (1) the number of courses with e-reserves

\begin{tabular}{|l|c|c|c|}
\hline \multicolumn{4}{|c|}{ TABLE 4} \\
\begin{tabular}{|l|c|} 
Number of Courses with Educational \\
Materials Posted to E-reserves
\end{tabular} \\
\hline & $\begin{array}{c}\mathbf{2 0 0 9 - 1 0} \\
(\mathbf{n = 8})\end{array}$ & $\begin{array}{c}\mathbf{2 0 0 8 - 0 9} \\
(\mathbf{n = 8})\end{array}$ & $\begin{array}{c}\mathbf{2 0 0 7 - 0 8} \\
(\mathbf{n = 9})\end{array}$ \\
\hline Maximum & 868 & 833 & 774 \\
\hline Minimum & 41 & 36 & 28 \\
\hline Mean & 346 & 334 & 287 \\
\hline Median & 150 & 145 & 145 \\
\hline
\end{tabular}




\begin{tabular}{|l|c|c|c|}
\hline \multicolumn{4}{|c|}{ TABLE 5 } \\
\hline & $\begin{array}{c}\mathbf{2 0 0 9 - 1 0} \\
\text { Tota) }\end{array}$ & $\begin{array}{c}\mathbf{2 0 0 8 - 0 9} \\
(\mathbf{n = 9 )}\end{array}$ & $\begin{array}{c}\mathbf{2 0 0 7 - 0 8} \\
(\mathbf{n = 9 )}\end{array}$ \\
\hline Maximum & 29,000 & 26,000 & 29,000 \\
\hline Minimum & 402 & 331 & 307 \\
\hline Mean & 4,094 & 3,811 & 1,940 \\
\hline Median & 2,100 & 4,300 & 5,400 \\
\hline
\end{tabular}

and (2) the total number of items posted to the e-reserve system, the low response rate makes it unwise to draw conclusions about these potential patterns beyond the institutions reflected in this dataset. Likewise, the apparent increase in both courses and items using e-reserves over the three-year period is impossible to generalize beyond these specific institutions.

Of all the responses, comparison between institutions of the total items posted in e-reserves would be one of the most interesting, because that is a key factor (fair use factor three-" "amount and substantiality") in use decisions. The responses indicate, however, a complete lack of uniformity in reporting. Some respondents indicated that the numbers reported were for the total number of pages (not items) posted, and others indicated that their reports captured "weblinks, scanned docs, [and] professor created docs," while others excluded those very same items. Still others indicated that the number of items reported was only a "best guess" or "approximate." This lack of uniformity, and the general inability to even produce these metrics (as compared to similar e-metric initiatives like COUNTER $^{21}$ ), makes comparison of practices among institutions a difficult task.

To understand the relationship between e-reserves and licensing, the survey also asked two licensing-related questions for the same threeyear time period: "What per- centage of these total items posted to e-reserves is estimated to be covered by existing institutional licenses (e.g., for content provided by JSTOR, Lexis-Nexis, ProQuest, Gale)?" (see table 6) and "How many of these total items were licensed specifically for inclusion in e-reserves?"

Like the questions regarding e-reserve implementation on campus, the response rate for these questions was low-just over 10 percent (12), as compared to 32 percent for the policy questions, perhaps indicating that this information was not known (as some respondents admitted). These responses that were received show that items posted under existing institutional licenses vary widely, raising questions about whether institutions have fully integrated institutional licensing schemes and e-reserves systems. The wide variability may also suggest variation in adoption of e-reserves systems - perhaps students are expected to use other tools outside the e-reserve system, such as the library catalog, to access these institutionally licensed materials. Any conclusions in this area must be somewhat speculative, as the responses reveal no obvious connection between the percentage of e-reserves items covered by institutional licenses and either the number of ereserve courses or the number of items posted on e-reserves. This means that, among the survey respondents, institutions with many e-reserve items and wide

\begin{tabular}{|l|c|c|c|}
\hline \multicolumn{4}{|c|}{$\begin{array}{c}\text { TABLE } 6 \\
\text { Percentage of Items Posted in E-reserves } \\
\text { Covered by Existing Institutional Licenses }\end{array}$} \\
\hline & \multicolumn{3}{|c|}{ Number of Institutions } \\
\hline & $\mathbf{2 0 0 9 - 1 0}$ & $\mathbf{2 0 0 8 - 0 9}$ & $\mathbf{2 0 0 7 - 0 8}$ \\
\hline More than $90 \%$ & 2 & 2 & 2 \\
\hline $75 \%$ to $90 \%$ & 1 & 1 & 1 \\
\hline $50 \%$ to $75 \%$ & 2 & 3 & 3 \\
\hline $25 \%$ to $50 \%$ & 2 & 2 & 2 \\
\hline $10 \%$ to $25 \%$ & 2 & 2 & 1 \\
\hline Less than $10 \%$ & 1 & 0 & 1 \\
\hline I am uncertain of the $\%$ & 2 & 2 & 3 \\
\hline
\end{tabular}


course-adoption of e-reserves are just as likely to rely on institutionwide licenses for e-reserves as those respondents with few courses and items using e-reserves.

The question "How many of these total items were licensed specifically for inclusion in e-reserves?" garnered an even lower response rate. Only five respondents knew and were willing to share this information. Like the responses to the other quantitative questions on e-reserves implementation and licensing, these responses were instructive not because of the trends that appeared but because of the lack of trends. Of the five responses, two indicated that no items were licensed specifically for e-reserves (one noting that " $[\mathrm{d}]$ ecisions about inclusion in ereserves almost exclusively based on fair use analysis"), while one stated that all items included were licensed. The two remaining responses stated that between 101 to 133 items were specifically licensed for e-reserves over the three years in question; but, even among these two institutions, the number of specifically licensed items as a percentage of total ereserve items posted varied significantly. For one institution, specifically licensed materials represented around 7 percent of total e-reserve items, while a similar number (100 or so items) represented only 1.5 percent of total e-reserve items at the other institution.

\section{Reactions to E-Reserves Services Policies and Practices}

Finally, the overwhelming majority of responding institutions had never been contacted by any publisher regarding potentially copyright-infringing uses of e-reserve materials. Of the thirty-five institutions that responded, only four (11\%) reported any contact. Those that were contacted-including those whose only contact was automated rejection of requests that exceeded the parameters of the Copyright Clearance Center's online system - all had reasonable resolutions to their issues. The one institution that received a letter threatening legal action reported, "We were able to contest every point as we kept very good records and could justify fair use for all uses. After our response we never heard back." With the high-profile Georgia State case in progress some may assume that litigation is common, but the responses in this study suggest otherwise. ${ }^{22}$ Litigation remains extremely rare, and even the threat of litigation is uncommon.

\section{Conclusions}

One of the most striking conclusions that can be drawn from these responses is that many institutions have limited means for managing and assessing their institutional practices with respect to e-reserves services. Many institutions simply lack information about the e-reserve systems in terms of the number of courses using the system, the number of items posted over a semester, or how much the university expended on licensing access to materials. Many respondents indicated that compiling these statistics was a difficult and uncommon task. Even for internal compliance with copyright policies, universities should take steps to ensure that these statistics are available. Furthermore, a lack of record keeping makes it impossible to compare practices from one institution to another. Since copyright analysis can be contextual and fact specific, comparison of both policy and practice to those of peer institutions is essential. The current lack of uniformity in terms of e-reserve collection statistics makes comparisons unwieldy, thereby stifling an accurate risk assessment on the part of librarians implementing those systems. Libraries should work to establish uniform standards to track and report these statistics.

At the same time, it is clear that libraries and their host institutions do care about complying with copyright law. Thirty of the thirty-two respondent libraries with e-reserves had policies governing the use of e-reserves, and over 80 percent of those with policies had updated them within the last five years. In creating those policies, libraries are looking at 
a wide variety of sources to draft their policies, most often turning to internal legal counsel, best-practice guides, and peer-institution policies for guidance. Yet, to the extent that libraries are looking at outside sources for guidance on policy creation, only two libraries reported actually contacting outside professionals at peer institutions regarding their policies or practice. This may not be surprising, given that most respondents were either unable or unwilling to share practical details on e-reserve implementation. To truly appreciate how library policy and practice compares with that of peer institutions, it is important that librarians actually talk to each other about the content and implementation of these policies. At present, policy creation is largely based on looking over the shoulders of peer institutions, while foregoing any real conversation on the issues.

Another issue revealed by this study is the overwhelming variability that exists across institutions in nearly every facet of electronic reserves. The numbers and types of items, as well as the policies themselves, all vary widely, with little obvious correlation to enrollment, endowment, level of prestige, or any other traditional metric.

Presumably there are lurking variables that explain some of this variety. It may be that an institution's technology policy or institutional stance on copyright issues plays a role. Competing sources of class material such as unmediated Content Management Systems or robust faculty web pages may offer alternate channels that limit the use of formal electronic reserves.

Further, the approaches adopted for licensing material for e-reserves seems to be just as varied. Some institutions simply make content from their main collection available or rely exclusively on fair use when using content. Those institutions that do license additional content specifi- cally for e-reserves also showed substantial variety in the proportion of licensed content to total content made available and in proportion to total content licensed in the collection.

In light of the legal risks and highprofile news items such as the Georgia State case, this wide variance in practice and policy may seem daunting. With such high stakes and so little common ground, what can institutions do to improve the state of the profession in this area? Despite these concerns, however, the final conclusion this paper offers is simply to relax. Only four institutions reported being contacted by publishers, and there is little evidence that publishers are targeting e-reserves for legal action.

Libraries should stay informed about copyright law and be mindful of the risks associated with providing access. But libraries should also take comfort in the panoply of rights afforded to them by the Copyright $\mathrm{Act}^{23}$ and their special place within the scholarly communication cycle.

The only way for practice to improve across the profession is for individual institutions to communicate. Libraries must share information so that they can accurately gauge the risks involved. Thoughtful discussion about past experience and current practice is also necessary to inform normative decisions about how practice should develop. Only through frank discussion with all stakeholders about current practice can the profession develop the set of best practices necessary to support legally appropriate assertion of our rights.

\section{Author note}

The study protocols discussed in this article were reviewed by the Behavioral Institutional Review Board at the University of North Carolina at Chapel Hill. Due to the nature of the collected data, this study (\#11-0335) was determined to be exempt from further review. 


\section{Appendix A. E-Reserves Survey Instrument}

Copyrighted materials in e-reserves policy, consent document

Dear participant,

Our names are Dave Hansen and Will Cross, and we are graduate students at the University of North Carolina at Chapel Hill supervised by Phillip M. Edwards, a member of the faculty at the School of Information and Library Science. We are conducting a research study on the ways in which ARL member-institutions make decisions about licensing and/or providing access to content for students via electronic reserves systems. The purpose of the research is to characterize the current state of practice and policy with respect to the development of electronic reserves systems.

The online survey, which will ask you questions about your institutions' practices and policies related to the interpretation of copyright law in the context of electronic reserves, should take 10-15 minutes of your time and is voluntary. You may stop taking the survey at any time, and you may skip any question for any reason. You will not receive any direct benefit from being in this research study. The only possible risk to you of participating in this research study might be embarrassment if your answers became public, but that is very unlikely. All possible measures have been taken to protect the confidentiality of your answers.

We will report only summaries of the aggregated data. This means that your responses will be combined with all of the other responses received and will not be able to be identified as yours. Deductive disclosure which is the discerning of an individual respondent's identity and responses through the use of known characteristics of that individual is also possible but unlikely. If you have any questions regarding this survey, you may contact us via email at drhansen@email.unc.edu or wcross@email.unc.edu. All research on human volunteers is reviewed by a committee that works to protect your rights and welfare. If you have any questions or concerns regarding your rights as a research subject you may contact, anonymously if you wish, the Institutional Review Board at (919) 966-3113 or via email at IRB_subjects@unc.edu with study number

By clicking 'I consent to participate' below and completing the survey, you agree to be a participant in this study. If you would rather not participate, please select 'I would rather not participate' below to remove your email address from this study.

Thank you,

Dave Hansen and Will Cross
( I consent to participate
I I would rather not participate

Copyrighted materials in e-reserves policy, screening questions

Does your campus currently offer students access to educational materials through an electronic reserves (e-reserves) system?
Yes
- No

Does your campus have an existing policy regarding the inclusion of copyrighted materials in e-reserves? 


\section{Appendix A. E-Reserves Survey Instrument}

Yes

No

Copyrighted materials in e-reserves policy, implementation and characteristics

How recently was this copyrighted materials policy evaluated or updated?

More than 10 years ago

5 to 10 years ago

2 to 5 years ago

1 to 2 years ago

Within the past year

Which sources did you refer to when drafting/updating this copyrighted materials policy for e-reserves?

Peer institutions' copyrighted materials policies

Best practices or guidelines produced by professional organizations

Solicited input from professionals via electronic mailing lists or other communication venues

Scholarly communications librarian on your campus

College/university legal counsel on your campus

Solicited input from the faculty council or a faculty committee on your campus

Other sources

Who is primarily responsible for monitoring adherence to this copyrighted materials policy for e-reserves?

- Your Director or other member of the library's administrative team

- Your copyright officer or scholarly communications librarian

- One or more librarians who directly administer e-reserves

o One or more paraprofessional staff members who directly administer e-reserves

- Faculty and instructors on your campus

Other individuals

Whenever permissions for copyrighted materials may be required, who is primarily responsible for communicating with the associated rights-holders?

o Your Director or other member of the library's administrative team

- Your copyright officer or scholarly communications librarian

One or more librarians who directly administer e-reserves

one or more paraprofessional staff members who directly administer e-reserves 


\section{Appendix A. E-Reserves Survey Instrument}

Faculty and instructors on your campus

Other individuals

For the remaining questions on this page, if available for any of the past three academic years (2009-2010, 2008-2009, and/or 2007-2008),...

How many courses on your campus have posted educational materials to e-reserves? [If multiple sections of a course (e.g., Psychology 101) have posted materials to e-reserves, please count this as a single course.]

\begin{tabular}{|c|c|c|c|c|}
\hline & 2009-2010 & 2008-2009 & 2007-2008 & $\begin{array}{l}\text { If you would like to } \\
\text { clarify how you } \\
\text { collect and report } \\
\text { these counts, } \\
\text { please do so here: }\end{array}$ \\
\hline $\begin{array}{l}\text { Number of courses with } \\
\text { materials in e-reserves }\end{array}$ & & & & \\
\hline
\end{tabular}

How many total items have been posted to e-reserves (including items made available through licensing, determined to fall under "fair use", excepted under the TEACH Act, produced by faculty or instructors, etc.)?

\begin{tabular}{|c|c|c|c|c|}
\hline & 2009-2010 & $2008-2009$ & $2007-2008$ & $\begin{array}{l}\text { If you would like to } \\
\text { clarify how you } \\
\text { collect and report } \\
\text { these counts, } \\
\text { please do so here: }\end{array}$ \\
\hline $\begin{array}{l}\text { Number of total items } \\
\text { within e-reserves }\end{array}$ & & & & \\
\hline
\end{tabular}

What percentage of these total items posted to e-reserves is estimated to be covered by existing institutional licenses (e.g., for content provided by JSTOR, Lexis-Nexis, ProQuest, Gale)?

2009-2010

2008-2009

2007-2008

How many of these total items were licensed specifically for inclusion in e-reserves?

\begin{tabular}{|c|c|c|c|c|}
\hline & 2009-2010 & 2008-2009 & $2007-2008$ & $\begin{array}{l}\text { If you would like to } \\
\text { clarify how you } \\
\text { collect and report } \\
\text { these counts, } \\
\text { please do so here: }\end{array}$ \\
\hline $\begin{array}{l}\text { mber of licensed items } \\
\text { thin e-reserves }\end{array}$ & & & & \\
\hline
\end{tabular}




\section{Appendix A. E-Reserves Survey Instrument}

How much did your campus expend to obtain licenses for copyrighted materials specifically for inclusion in e-reserves?

\begin{tabular}{|c|c|c|c|c|}
\hline & $2009-2010$ & $2008-2009$ & $2007-2008$ & $\begin{array}{l}\text { If you would like to } \\
\text { clarify how you } \\
\text { collect and report } \\
\text { these expenditures, } \\
\text { please do so here: }\end{array}$ \\
\hline $\begin{array}{l}\text { Licensing expenditures (in } \\
\text { U.S. dollars) for e-reserves }\end{array}$ & & & & \\
\hline
\end{tabular}

\section{Copyrighted materials in e-reserves policy, legal challenges and resolutions}

Who makes the threshold decision regarding contested uses of e-reserve content?

6. University counsel

- Full time copyright/ scholarly communications librarian

- Librarians who administer e-reserves

Faculty or instructor

O Other

What stakeholders are involved in evaluating and responding to publishers and rights holders regarding potentially infringing uses of e-reserve content? (check all that apply).

- University counsel

Full time copyright/ scholarly communications librarian

Librarians who administer e-reserves

Faculty or instructor

Other

Have you ever been contacted by a publisher or rights-holder regarding potentially copyright-infringing uses of e-reserve materials?

- Yes

- No

If you have been contacted by a publisher or rights-holder, please describe the circumstances of that contact as well as how those concerns/issues were resolved. 


\section{Appendix A. E-Reserves Survey Instrument}

\begin{tabular}{l} 
Copyrighted materials in e-reserves policy, upload/URL \\
\hline $\begin{array}{l}\text { Please upload an electronic copy your institution's policy regarding the inclusion of copyrighted } \\
\text { materials in e-reserves, or... } \\
\text { Browse. }\end{array}$ \\
\hline
\end{tabular}

If your campus has posted the policy regarding the inclusion of copyrighted materials in e-reserves on the Web, please supply the URL of that document below.

\section{Notes}

1. William M. Cross and Phillip M. Edwards, "Pre-Service Legal Education for Academic Librarians within ALA-Accredited Degree Programs," portal: Libraries and the Academy 11, no. 1 (2011):533-50.

2. Donna L. Ferullo, "Major Copyright Issues in Academic Libraries: Legal Implications of the Digital Environment," Journal of Library Administration 40, no.1 (2004): 23-40.

3. G. Edward Evans and Margaret Z. Saponaro, Developing Library and Information Center Collections, 5th ed. (Westport, Conn.: Libraries Unlimited, 2005), 53.

4. Steven J. Melamut, "Pursuing Fair Use, Law Libraries, and Electronic Reserves," Law Library Journal 92, no. 2 (2000): 157-92.

5. 17 U.S.C. $\S 107$ (2006).

6. Pub. L. 107-273, div. C, title III, $\S \S 13301,116$ Stat. 1758, 1910 (2002) (codified at 17 U.S.C. $\S 110(2)(2006))$.

7. Peter B. Hirtle, Emily Hudson, and Andrew T. Kenyon, Copyright and Cultural Institutions (Ithaca: Cornell University Library 2009), 39-65.

8. Kevin Smith, "How Efficient Is Our Licensing System?" Scholarly Communication @ Duke blog, available online at http://blogs.library.duke.edu/scholcomm/2010/02/24/how-efficient-is-ourlicensing-system/ [accessed 11 August 2011].

9. Leah G. McGinnis, "Electronic Reserves at the University of North Carolina: Milestones and Challenges to Implementing a New Service," Journal of Interlibrary Loan, Document Delivery, and Information Supply 9, no. 4 (1999): 73-85.

10. Cambridge Univ. Press v. Becker, Civil Action No. 1:08-CV-1425-ODE (ORDER, Sept. 30, 2010).

11. 17 U.S.C. $§ 107$ (2006).

12. Deborah Gerhardt and Madelyn Wessel, "Fair Use and Fairness on Campus," North Carolina Journal of Law \& Technology 11 (Spring 2010): 461, 466.

13. James Gibson, "Risk Aversion and Rights Accretion in Intellectual Property Law," Yale Law Journal 116, no.1 (2007): 882, 887.

14. Ibid.

15. Pnina Shachaf and Ellen Rubenstein, " A Comparative Analysis of Libraries' Approaches to Copyright: Israel, Russia \& the U.S.," The Journal of Academic Librarianship 33, no. 1 (2007): 94-105; Kathryn Ann Loggie et al., "An Analysis of Copyright Policies for Distance Learning Materials at Major Research Universities," Journal of Interactive Learning 5, no. 3 (2006): 224-42; Kimberly B. Kelley, "Intellectual Property, Ownership and Digital Course Materials: A Study of Intellectual Property Policies at Two- and Four-Year Colleges and Universities," portal: Libraries and the Academy 2, no. 2 (2002): 255-66.

16. Leah G. McGinnis, "Bringing Order out of Chaos: The Challenge of Managing E-Reserves Copyright Permissions," Journal of Interlibrary Loan, Document Delivery, and Information Supply 11, no. 2 (2000): 39-49.

17. Victoria H. Wagner, "Processing Reserves, Seeking Permissions and Engaging the Campus," Journal of Interlibrary Loan, Document Delivery \& Electronic Reserve 18, no. 2 (2008): 247-54. 
18. Thomas H.P. Gould, Tomas A. Lipinski, and Elizabeth A. Buchanan, “Copyright Policies and the Deciphering of Fair Use in the Creation of Reserves at University Libraries," The Journal of Academic Librarianship 31, no. 3 (2005): 182-97.

19. U.S. Dept. of Education, National Center for Education Statistics, IPEDS Data Center, available online at http://nces.ed.gov/ipeds/datacenter/ [accessed 24 April 2011].

20. American Library Association, "Guidelines on Fair Use and Electronic Reserves," available online at http://www.ala.org/advocacy/copyright/fairuse/fairuseandelectronicreserves [accessed 15 November 2012].

21. http://www.projectcounter.org/

22. Since this article was accepted for publication the District Court for the Northern District of Georgia ruled in Cambridge University Press v. Becker, 863 F.Supp.2d 1190 (N.D. Ga. 2012), finding that of the publishers' 75 alleged infringements that were submitted to the court for resolution, only five excerpts of four different books were actually infringing. On the whole the court concluded that the fair use analysis tilted in favor of the university in that case when the university's purpose was educational and non-profit (which it always was), when the use of the work was "decidedly small" (in this case, less than $10 \%$ of the book, or one chapter in longer books), and when licenses to use the work were not "easily accessible, reasonably priced, and [offered] in a format which is reasonably convenient for users" (e.g., digital licenses). The publishers are currently appealing the decision of the district court. See Cambridge University Press v. J.L. Albert, Case no. 12-14676, Notice of Appeal (11th Cir. Sept. 12, 2012).

23. William M. Cross, "The State of the Scholarly Communication Librarian," (master's paper, University of North Carolina at Chapel Hill, 2011).

\section{Join us at the ACRL/LLAMA Joint Presidents' Program during the ALA Annual Conference in Chicago, IL on Saturday, June 29, 2013}

\section{ACRL) \\ (6)LLAMA Standing on Marbles: Ensuring Steady Leadership in Unsteady Times}

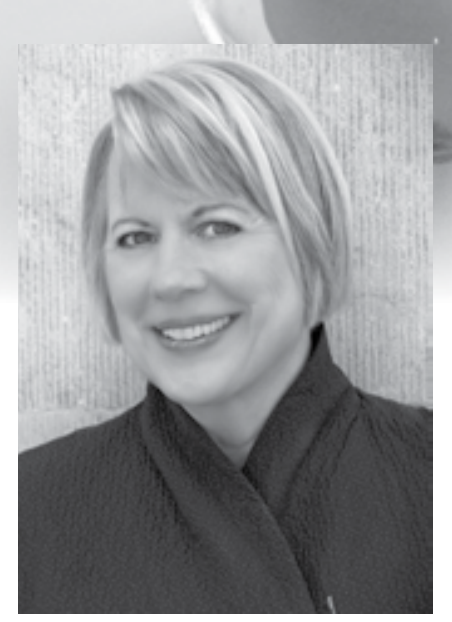

Dr. Karol Wasylyshyn
Based on nearly three decades of leadership consultation to business organizations, clinical psychologist, global pioneer of executive coaching, author and poet, Dr. Karol Wasylyshyn, will discuss her leadership research and experiences working with senior leaders. With an eye toward the potential applicability of her findings to the challenges facing leaders in libraries of all kinds, she will describe three common patterns of leadership behavior and illustrate them through free verse or what she terms leadership vignettes. Attendees will be invited to consider their own ways of leading through this provocative use of metaphorical thought. 